\section{Los Factores de Riesgo de Conducta AntiÉtica según el Modelo de Donald R. Cressey aplicado a la Universidad Nacional Mayor de San Marcos}

\author{
The Risk Factors of Anti-Ethical Conduct according to the \\ Model of Donald R. Cressey applied to the National University \\ of San Marcos
}

\begin{abstract}
RESUMEN
Las investigaciones en torno a la corrupción de funcionarios destacan que para materializar la corrupción es necesario que existan tres condiciones fundamentales: la oportunidad, la racionalización y el poder; por ello, el presente artículo analiza las causas de las conductas antiéticas en la función pública y de la racionalización en la justificación de las conductas antiéticas. En este sentido es necesario regular y fiscalizar la conducta funcional del empleado público en el ejercicio de sus actividades institucionales, puesto que sus labores las desarrolla en base a la ética de la función pública que dirige toda la actividad estatal, que se nutren de posturas éticas fundamentales que le proporcionan coherencia y finalidad. Por ello, es indispensable no sólo regular y denunciar sino sancionar las conductas deshonestas de los funcionarios. En este sentido, consideramos que el problema fundamental está relacionado con la antimoral del corrupto y su intento de justificar su conducta en base a la racionalización y para ello utilizamos el modelo de interpretación del Triángulo del Fraude de Donald R. Cressey. La predisposición al fraude (corrupción) se estableció en base a encuestas anónimas aplicadas a los funcionarios de nivel medio de la Universidad Nacional Mayor de San Marcos.
\end{abstract}

Palabras claves: Corrupción; Racionalización; Cressey.

\begin{abstract}
Investigations into the corruption of officials highlight that in order to materialize corruption it is necessary that there are three fundamental conditions: opportunity, rationalization and power; Therefore, this article analyzes the causes of unethical behaviors in public service and rationalization in the justification of unethical behaviors. In this sense, it is necessary to regulate and supervise the functional behavior of the public employee in the exercise of their institutional activities, since their work is carried out based on the ethics of the public function that directs all state activity, which are nourished by ethical positions fundamentals that provide consistency and purpose. Therefore, it is essential not only to regulate and denounce but to punish the dishonest conduct of officials. In this sense, we consider that the fundamental problem is related to the anti-
\end{abstract}

Walter David Ugarte Casafranca $^{1}$

wugartec@unmsm.edu.pe

Teresa Victoria Melgar Campos $^{1}$

victoriamc5@hotmail.com ${ }^{1}$ Universidad Nacional Mayor de
San Marcos, Facultad de Ciencias
Administrativas. Lima, Perú 
moral of the corrupt and their attempt to justify their behavior based on rationalization and for this, we use the interpretation model of the Triangle of Fraud by Donald R. Cressey. The predisposition to fraud (corruption) was established based on anonymous surveys applied to mid-level officials of the National University of San Marcos.

Keywords: Corruption; Rationalization; Cressey.

\section{INTRODUCCIÓN}

\section{Corrupción de funcionarios.}

En el Perú los estudios sobre la corrupción se han centrado fundamentalmente en el establecimiento de las responsabilidades de los funcionarios públicos para la consiguiente sanción administrativa, civil o penal. Estos estudios son realizados por el periodismo nacional en su mayor parte. En el extranjero encontramos la investigación de Alejandro Estévez (2005) relacionada con la corrupción de funcionarios en Venezuela.

En cuanto a la ética profesional, los estudios se centran en la investigación axiológica teórica y el impacto social de la corrupción.

Encontramos, sobre este asunto, abundante bibliografía e información digital en los buscadores de internet. En la Universidad Nacional Mayor de San Marcos, la Dra. Jeri Ramón (2014) presenta un artículo de investigación sobre la ética y la función pública.

\section{Noción de Corrupción.}

Existen diferentes conceptos acerca de corrupción, tal como mencionaremos a continuación:

Nouel (2006) sobre la corrupción sostiene:

el núcleo de la corrupción no se encuentra en el interés público, el daño o en el abuso de la posición, sino en la deslealtad hacia el ordenamiento normativo que debería seguir alguien que se presupone es su servidor y que por tanto tiene una relación especial con él. (p. 212)

Garzón (2001) indica:

El concepto de corrupción está lógicamente vinculado con el sistema normativo. No es posible hablar de corrupción sin hacer referencia simultáneamente al marco normativo dentro del cual se pro- duce el acto o la actividad calificada de corrupta. Llamaré al sistema normativo con respecto al cual un acto o una actividad es calificado (a) de corrupto (a) sistema normativo relevante. (p. 209)

La ONU (2001) sostiene que "la corrupción es una relación de intercambio entre el responsable de tomar las decisiones y un interesado que ofrece o promete una ventaja a cambio del resultado deseado de una decisión," (p. 82). Es el cambio normal de una decisión por medio de entrega de algún bien para obtener decisiones distintas a las normadas en la sociedad, así lograr ciertos resultados.

Así la corrupción tiene un carácter público privado, es decir cuando las normas sociales son alteradas por personas del sector privado quienes ofrecen viene para que los funcionarios públicos decidan a favor de estos, de esta manera también se altera y corrompen las leyes.

Contreras quien cita a Paz, K. (2000) indica que:

Es común hablar de corrupción en todos lados, de cómo este problema afecta a la sociedad y las consecuencias que esta ocasiona en el entorno económico, social, cultural, en la infraestructura de un estado y en la manipulación de la información que el estado proporciona a la ciudadanía, con el fin de hacer creer que todo está bien y que cada vez este problema social está mejor controlado. (p. 161).

La corrupción genera problemas en diferentes factores humanos, siendo especialmente en el problema económico, motivo por el cual debe ser controlado para no crear crisis en la sociedad. De esta forma la corrupción va en contra del modelo económico puesto que atenta contra la libre competencia, creando condiciones favorables a las empresas corruptas. 
De acuerdo a Zañartu (1996):

Se corrompen entonces el Estado y el mercado, que dejan de alcanzar de manera eficiente los objetivos que les son propios. El Estado se corrompe en cuanto muchas decisiones concretas no se toman en base a lo establecido por la ley o a la prudencia que atiende al bien público, sino sobre consideraciones particulares. El mercado se corrompe por cuanto poseer buenos contactos provee ventajas en la competencia no relacionadas con mejoras en el servicio que se presta a otros. Estado y mercado se interpenetran entonces de manera viciosa: por una parte, se hace posible establecer contratos privados con funcionarios públicos en que se compran decisiones públicas; por otra, uno se presenta en la competencia mercantil provisto de recursos coactivo del estado, que ha privatizado ilegítimamente. (pp. 50-51)

En los medios públicos existen empleados públicos que se corrompen por dinero de funcionario privados, quienes son favorecidos por licitaciones públicas, estos casos de corrupción degeneran la funcionalidad del Estado.

De acuerdo a la Oficina Internacional del Trabajo (2007):

La corrupción es un problema tanto en el sector público como en el privado porque consta de elementos del lado de la demanda (por ejemplo, los funcionarios públicos deseosos de aceptar sobornos) y del de la oferta (por ejemplo, los miembros de empresas privadas deseosos de pagarlos). Por motivos evidentes, se trata de un tema delicado políticamente y complejo. Hay distintas definiciones de la corrupción, y lo que en algunas sociedades se considera que es corrupción, podría ser un comportamiento social aceptable en otras, por ejemplo, las actitudes con respecto a ofrecer regalos, utilizar información privilegiada para lucrarse personalmente, determinados tipos de nepotismo y concepciones acerca de cuándo se produce un conflicto de intereses... (p. 142)

La corrupción de funcionarios públicos a través de sobornos altera la normatividad públi- ca, para favorecer a otras personas y degenera el comportamiento de las personas, a pesar de ello hay quienes justifican este accionar negativo.

Pérez (2004) sostiene:

...la corrupción tradicionalmente se ha considerado siempre como un delito típico y exclusivo del sector público: los varios tipos penales que el Código penal destina a reprimir este fenómeno delictivo...es decir, aquel que pretende o recibe la dádiva o la promesa de dinero u otro favor - debe ser un sujeto que puede ser funcionario público o encargado de un servicio público...también a algunos sectores de actividad económica privada: se ha considerado, por ejemplo, que constituía corrupción el pago de sumas de dinero (tangenti) a los administradores de una sociedad constituida para la gestión, en régimen de concesión pública...(p. 327)

La corrupción se constituye como un acto delictivo en contra de las normas del Estado favoreciendo a uno y destruyendo el derecho de otros, en este accionar intervienen el sujeto que decide una acción y otro que entrega un bien, ambos son cómplices de la corrupción.

Uno de los peligros de la corrupción de funcionarios en nuestro país consiste en el hecho, recientemente divulgado a partir de las investigaciones periodísticas, del vínculo entre el crimen organizado, los financistas de los partidos políticos y la administración pública. La complicidad entre algunos de los representantes de los poderes del Estado, los funcionarios públicos y las organizaciones criminales crean una estructura de impunidad en la que resulta paradójico que la criminalidad ha llegado a tener que combatirse a sí misma como lo anotara (Hassemer 1995).

En esta situación, la lucha contra la corrupción, supone una necesaria reestructuración del Estado y el establecimiento de sistemas de control más eficaces en el nombramiento y seguimiento de los funcionarios públicos. Los protocolos de los concursos públicos de nombramiento y contratación han de ser mejorados, estableciendo requisitos básicos de idoneidad académica y moral. 


\section{Nociones de Ética.}

El concepto de ética tiene varios conceptos, de las que mencionares algunas con las cuales compartimos afinidad y serán útiles para nuestra investigación. Tal como se detalla a continuación:

El término ética deriva del griego éthos cuyo significado es costumbre, pero la referencia es las buenas costumbres y no otras.

De acuerdo a la etimología Cortina y Martínez (2008) sostienen

A menudo se utiliza la palabra ética como sinónimo de lo que anteriormente hemos llamado la moral, es decir, ese conjunto de principios, normas, preceptos y valores que rigen la vida de los pueblos y de los individuos. La palabra ética procede del griego ethos, que significaba originariamente "morada", "lugar donde vivimos", pero posteriormente pasó a significar "el carácter", el "modo de ser" que una persona o grupo va adquiriendo a lo largo de su vida... (p. 21)

De esta manera se comprende como costumbre a las normas de convivencia establecidas dentro de un grupo social, cuya convicción es vivir armoniosamente entre sujetos de una misma comunidad.

Para Rojas (2005) la ética consiste en:

el estudio racional y crítico de los valores morales. Como estudio racional, la ética utiliza métodos filosóficos para su investigación (análisis, síntesis, crítica del lenguaje, etc.). En cuanto crítica, la ética no se circunscribe al estudio de la moral vigente, puede abordar los temas de la ética en forma cuestionadora. La ética no puede ser neutral, porque los estudios de los valores morales no pueden hacerse sin tomar una posición valorativa. Eso hace que haya múltiples teorías éticas, del mismo modo que en la introducción a la filosofía pudimos constatar que hay muchas filosofías. Especialmente la idea acerca de lo que es bueno, el bien y el mal, son conceptos que generan muchas divergencias y teorías muy diferentes. (p. 124)

La ética también alude al estudio de los valores asumidos por los miembros de una comu- nidad para criticarlos y tener un conocimiento profundo y exhaustivo de los mismos, pero de manera conceptual.

La ética es concebida como la acción humana frente a los problemas y la convivencia diaria con otros; siendo la finalidad del hombre lo bueno, es decir el hombre debe buscar ser bueno para convivir bien.

Incide García (1987) sobre la ética:

La materia de la ética es la conducta humana, o sea, aquellos actos que el individuo ejecuta en forma voluntaria y de los que resulta por ello responsable. El punto de vista desde el cual la ética estudia la conducta humana es el bien y el mal, de lo que debe hacer y de lo que no debe hacer. El verdadero verbo de la ética es "debe". A la ética le interesa aquello que "debe" o "debería ser". A pesar de las opiniones diversas en torno a la ética, hay algo en lo que todos coinciden y en el "debe ser", característico de la esfera de la ética. (p. 224)

La ética tiene como condición el "deber ser" es decir el deber del hombre por actuar de una determinada manera, para ello se recurre a los comportamientos adquiridos en la sociedad según sus modelos de "bondad" o bien.

La libertad, entonces es la condición sine qua non de la valoración ética de una conducta o acción humana.

Sobre la ética Etxeberria; (1995) sostiene

Habrá que tener en cuenta, de todos modos, esta autora, que, dado que la tarea de la ética no es solucionar casos concretos sino diseñar los valores, principios y procedimientos que los afectados deberán luego tener en cuenta en los diferentes casos, la ética como tal no se plantea las aplicaciones concretas sino el diseño del marco de la aplicación. (p. 24)

Concebimos la ética entonces como un modelo de acción. Es decir, como una estructura sin contenido conductual concreto sino como una forma de valoración de las conductas concretas.

Entonces la ética parte del convencimiento que se tiene de la justeza de una conducta, 
en el sentido de la realización de un valor social determinado. Esto se aplica en la conducta personal, así como la que esperamos de los demás.

\section{Asimismo, para Sánchez (2005):}

De la misma manera que, estando estrechamente vinculados no se identifican los problemas teóricos morales con los problemas prácticos, tampoco pueden confundirse la ética y la moral. La ética no crea la moral. Aunque es cierto que toda moral efectiva supone ciertos principios, normas o reglas de conducta, no es la ética la que, en una comunidad dada, establece esos principios, o normas. o sea, con una serie de morales efectivas ya dadas, y partiendo de ellas trata de establecer la esencia de la moral, su origen, las condiciones objetivas y subjetivas del acto moral, las fuentes de la valoración moral, la naturaleza y función de los juicios morales, los criterios de justificación de dichos juicios, y el principio que rige el cambio y sucesión de diferentes sistemas morales. (pp. 24-25)

La ética es la reflexión sobre actos morales producto de un ejercicio interno, teórico, cuya finalidad es definir los fundamentos filosóficos, las características y requisitos de un acto moral. La moral, en cambio, se refiere a las acciones humanas y a la esfera de valores y reglas definidas que regulan la convivencia dentro de un grupo o cultura definiendo cómo los integrantes y extraños deben comportarse en dicho entorno social.

Además, acota Sánchez (2005) que la ética "es la teoría o ciencia del comportamiento moral de los hombres en sociedad. 0 sea, es ciencia de una forma específica de conducta humana" (p. 25). Así la ética estudia objetivamente la conducta humana para establecer principios.

Según García (1996):

La ética, en general, es un saber práctico que nos enseña a actuar y decidir correctamente... Por eso entendemos por responsabilidad ética de la empresa el cumplimiento de los intereses de todos los grupos implicados en la actividad empresarial. El objetivo de la empresa es, y debe ser, maximizar el beneficio, pero lo que sea el beneficio, está en función del cómo y del para quién. Si para conseguir beneficio los accionistas o socios, debe perjudicarse a los trabajadores, producir servicios de mala calidad, contaminar el medio ambiente, incumplir los contratos, etc., es una señal evidente de que algo no van bien. La responsabilidad ética constituiría en definitiva el horizonte de actuación para la definición de la responsabilidad social y ecológica. (p. 19)

Por otro lado, Barquero (2003) define la ética indicando que en concreto, "la ética, como ciencia de la conducta, tiene como fin el estudio del problema del bien y del mal y de la felicidad del hombre, como ser racional que actúa en libertad" (p. 35).

De acuerdo a Polo (2004) existen cuatro versiones para entender la ética y moral que quizás sean las más comunes:

Primera versión. Académicamente suele considerarse a la ética como una disciplina teórica que pertenece a la filosofía cuya tarea es estudiar la moral...Segunda versión. La ética sería el ámbito de las decisiones y acciones que afectan a la familia, la sociedad y al Estado, es decir la ética como una actividad social y política. Mientras que la moral sería el ámbito de la subjetividad: pensamientos, sentimientos, voluntad deseos e intereses... Tercera versión. La ética es el arte de aprender a vivir bien, por lo tanto, abarca y trasciende lo moral, porque busca una vida armónica articulada con las distintas dimensiones de la vida humana. La moral es el ámbito personal-social donde experimentamos con valores, normas, juicios, etc., contenidos y transmitidos por la tradición...Cuarta versión. Es aquella que no hace ninguna distinción entre ética y moral, ya que todo se da en la misma realidad... (pp. 17-20)

En la ética existen diferentes concepciones sea como disciplina, sea como normas de comportamiento, sea como costumbres culturales desde la familia, se somete a la realidad social, al mismo tiempo en ellas se aprecia el compor- 
tamiento humano como centro de la ética y el modo de vida en la sociedad.

Por ello, la ética desde una perspectiva teórica permite desarrollar principios aplicables en la sociedad y en ese mismo sentido alude al modo de convivencia normativa entre las personas que integran una sociedad u organización social para convivir de manera armoniosa y lograr un buen clima social, es decir llegar a la felicidad.

\section{La moral.}

El término "moral" se utiliza frecuentemente como sinónimo de "costumbre", en el sentido de actitudes y conductas aceptadas por una comunidad.

Para Boff, (2003) "la moral forma parte de la vida concreta. Trata de la práctica real de las personas que se expresan por costumbres, hábitos y valores aceptados. Una persona es moral cuando obra conforme a las costumbres y valores establecidos que, eventualmente, pueden ser cuestionados por la ética. Una persona puede ser moral (sigue las costumbres) pero no necesariamente ética (obedece a principios)" (p.15).

La palabra moral deriva del latín "moralis" que significa costumbre. La palabra moral es que se hace por costumbre. Por ello, lo que se considera moral en una determinada sociedad, cultura o etnia, puede no serlo en otra. Asimismo, los criterios morales cambian a través del tiempo en función de la movilidad cultural y social.

Boff (2003) subraya adicionalmente que toda moralidad "tiene implícita un tipo de ética, pero no viceversa; decía anteriormente que la ética se puede poner en códigos, lo que hay que añadir aquí es que cuando estos códigos de comportamiento son aceptados por la mayoría de personas de un grupo se convierten en moral" (p.16).

\section{El Triángulo del Fraude.}

Donald Cressey (1961), desarrolló un modelo pertinente y fundamentado que explica los principios que impulsan a las personas moralmente intachables que cometen fraude. Este modelo es conocido como "El Triángulo del Fraude". La investigación se llevó a cabo con personas corruptas a quienes llamó "violadores de la confianza". En el modelo de Cressey se dis- tinguen tres factores que condicionan la moralidad para que una persona común se convierta en corrupta.

El triángulo del fraude se sustenta los tres vértices más importantes para que se cumpla el fraude como el poder, la racionalización y la oportunidad. Estos factores según Cressey (1961) se detallan a continuación:

1. Poder (incentivo/presión): Los funcionarios de alto nivel o sus colegas son persuadidos o están sometidos a presión, lo que les proporciona una justificación para la corrupción.

2. Oportunidad: Se refiere a las circunstancias de un entorno ausente de controles, controles ineficaces o la incapacidad que tiene el Estado o la organización para sostener económicamente el control, lo cual otorga la oportunidad de cometer un acto de corrupción.

3. Racionalización/actitud: Es un mecanismo de defensa que es instrumentalizado por los funcionarios públicos o personas comunes que les permite justificar racionalmente un acto fraudulento para poder incluirlo, sin contradicciones, en su ética personal. Generalmente, previo al acto fraudulento, que poseen una actitud permisiva hacia la corrupción, o sus valores personales forman una base de antivalores que los impulsan, consciente e intencionalmente a cometer un acto deshonesto.

El fraude en las organizaciones productivas y en especial la financiera ha sido un problema social en el Perú, ello ha motivado el desarrollo de normas para superar dichos problemas éticos. Asimismo, ha establecidos lineamientos de prevención, detección y combate del fraude en las organizaciones productivas y financieras. Las entidades estatales y las empresas con responsabilidad social se basan en principios básicos y racionales de equidad, la honestidad, la solidaridad y la justicia. Esto afecta tanto a los grupos de interés como para la sociedad en general, que no puede verse afectada por los actos de funcionarios corruptos camuflados en las organizaciones, las empresas públicas y los organismos del Estado. 
Cressey (1961) considera que las personas con altos estándares de moralidad, posiblemente se les hace difícil cometer un fraude. Pero aquellas personas sin principios siempre encuentran una excusa y justifican su accionar, estos sostienen que no hay nada malo en lo que están haciendo. De este modo cualquier acción de fraude suele ser justificada, como entregar un producto más barato en vez del más caro, entregar un producto con marca cambiada, de cambiar la numeración de un calzado para venderlo, aumentar el precio de un producto, exagerar los costos de un crédito, etc. Los medios informáticos también están siendo adaptados para obtener beneficios económicos a través de fraudes a bancos, intercambios bancarios, extorsiones financieras, y otras.

La racionalización, según esta perspectiva, se centra fundamentalmente en la justificación que realiza el empleado público para cometer in acto inmoral o delito de corrupción. Para evitar el conflicto moral o la frustración ética que le causa la comisión de un crimen, se otorga a sí mismo razones desarrolla argumentos que ocultan, justifican o encubren los fallos o contrariedades. Su racionalización busca razones para justificar sus actos que serían vividos como conflictivos. Por lo general, luego de realizado el acto y pasado un cierto tiempo, no lo consideran tan malo. Esta defensa psicológica les permite aceptar sus delitos con un mínimo de remordimiento.

El mecanismo de defensa de la racionalización según Galor, (2013) es un "exceso en la aplicación de la lógica y del pensamiento abstracto como forma de evadir la experiencia de las emociones. El resultado es la separación de la experiencia afectiva respecto de la situación dolorosa". Esta se desarrolla fundamentalmente a partir de una deconstrucción de la realidad objetiva y la elaboración de una nueva versión que proporcione al individuo, de un motivo superior o de lo cotidiano de la corrupción, que disfraza los motivos que llevaron a la persona a realizar un acto de corrupción.

Por lo tanto, la racionalización es solo un intento de explicación superficial y tranquilizante que no evidencia las motivaciones íntimas de la conducta corrupta.
Sin embargo, debemos diferenciar la racionalización de la intelectualización. Éste último hace que el individuo se desconecte de su realidad sensorial, y utilice la razón para escapar de sí mismo cada vez que alguna emoción o deseo propio le resulta amenazante. Para evitar sufrir las consecuencias del presente, el quien intelectualiza una situación niega o inhibe sus sentimientos para activar su racionalidad o conocimientos a fin de no sentir la carga emotiva de sus conductas. En la intelectualización no se construye un argumento, simplemente, el sujeto se desconecta de sus propias emociones.

\section{MÉTODOS}

El diseño de la investigación es exploratoria descriptivo y no-experimental. Se describen los hechos tal y como se presentan, aportando datos no probabilísticos. La población son los funcionarios públicos, docentes y no docentes, de la Universidad Nacional Mayor de San Marcos. El tamaño de la muestra es de 52 funcionarios de alto nivel. Se ha utilizado la prueba no paramétrica Kendall Tau. Estudiamos la función de la racionalización en la justificación de las conductas anti-éticas. Desarrollamos una investigación que intenta demostrar la relación entre la racionalización y el nivel del funcionario. El problema fundamental está relacionado con la antimoral del corrupto y su intento de justificar su conducta en base a la racionalización. El modelo de interpretación se basa en el triángulo del fraude de Donald R. Cressey. La predisposición al fraude (corrupción) se estableció en base a encuestas anónimas aplicadas a los funcionarios de nivel medio de la Universidad Nacional Mayor de San Marcos.

Revisamos la bibliografía relacionada con el tema de investigación. Elaboramos las encuestas en torno a la percepción de las conductas anti-éticas. Aplicamos las encuestas a la muestra indicada en la metodología. Desarrollamos las entrevistas. Discutimos los resultados de los datos obtenidos y formulamos las conclusiones y recomendaciones.

\section{RESULTADOS Y DISCUSIÓN}

De la aplicación de encuestas a los funcionarios de la Universidad Nacional Mayor de San Marcos hemos obtenido los siguientes resultados: 
Tabla 1

Pregunta: comparto la idea de hacer obras y llevarse algo a casa

\begin{tabular}{llcccc}
\hline & & Frecuencia & Porcentaje & Porcentaje válido & Porcentaje acumulado \\
& Muy en desacuerdo & & & & 26,3 \\
\multirow{4}{*}{ Válido } & 15 & 25 & 43,3 & 43,9 & 26,3 \\
& En desacuerdo & 8 & 14,0 & 14,0 & 70,2 \\
& Indiferente & 4 & 7,0 & 7,0 & 84,2 \\
& De acuerdo & 5 & 8,8 & 8,8 & 1,2 \\
& Muy de acuerdo & 57 & 100,0 & 100,0 & 100,0 \\
\hline
\end{tabular}

Nota: Más del 15\% de los entrevistados manifiestan que es posible justificar los actos de corrupción si “se hace obra”. Esto constituye una manifestación del mecanismo de la racionalización. Fuente: elaboración propia.

Tabla 2

Pregunta: Enfrento exigencias económicas por mi estilo de vida diferente

\begin{tabular}{llcccc}
\hline & Frecuencia & Porcentaje & Porcentaje válido & Porcentaje acumulado \\
& Muy en desacuerdo & 3 & 5,3 & 5,3 & 5,3 \\
\multirow{2}{*}{ Válido } & En desacuerdo & 16 & 28,1 & 28,1 & 33,3 \\
& Indiferente & 15 & 26,3 & 26,3 & 5,3 \\
& De acuerdo & 18 & 31,6 & 31,6 & \\
& Muy de acuerdo & 5 & 8,8 & 8,8 & 1,2 \\
& Total & 57 & 100,0 & 100,0 &
\end{tabular}

Nota: El 40\% de los encuestados manifiestan presión económica para satisfacer sus necesidades. Esto constituye una circunstancia de peligro institucional. Fuente: elaboración propia.

Tabla 3

Pregunta: Siento ambición en el sentido amplio del término

\begin{tabular}{llcccc}
\hline & & Frecuencia & Porcentaje & Porcentaje válido & Porcentaje acumulado \\
& Muy en desacuerdo & 6 & 10,5 & 10,5 & 10,5 \\
\multirow{4}{*}{ Válido } & En desacuerdo & 16 & 28,1 & 28,1 & 38,6 \\
& Indiferente & 11 & 19,3 & 19,3 & 37,1 \\
& De acuerdo & 20 & 35,1 & 7,0 & 100 \\
& Muy de acuerdo & 4 & 7,0 & 100,0 & 100 \\
\end{tabular}

Nota: El 42\% de los encuestados se consideran a sí mismos ambiciosos. Fuente: elaboración propia.

Tabla 4

Pregunta: Conozco los procesos administrativos y suficiente poder sobre los recursos y las personas

\begin{tabular}{llcccc}
\hline & Frecuencia & Porcentaje & Porcentaje válido & Porcentaje acumulado \\
\multirow{3}{*}{ Válido } & & & & 52,6 & 52,6 \\
& En desacuerdo & 30 & 52,6 & 28,1 & 80,7 \\
& Indiferente & 16 & 28,1 & 19,3 & 100,0 \\
& De acuerdo & 11 & 19,3 & 100,0 & \\
\end{tabular}

Nota: El 20\% de los funcionarios de alto nivel consideran que pueden tomar decisiones personales sobre los destinos de los recursos y las personas. Fuente: elaboración propia.

Tabla 5

Pregunta: Asumo riesgos, exceso de confianza y presión sobre los resultados.

\begin{tabular}{llcccc}
\hline & Frecuencia & Porcentaje & Porcentaje válido & Porcentaje acumulado \\
& Muy en desacuerdo & 4 & 7,0 & 7,0 & 7,0 \\
\multirow{4}{*}{ Válido } & En desacuerdo & 19 & 33,3 & 33,3 & 40,4 \\
& Indiferente & 11 & 19,3 & 19,3 & 4,3 \\
& De acuerdo & 23 & 40,4 & 100,0 \\
\end{tabular}

Nota: El 40\% de los encuestados asumen que la administración pública les permite asumir riesgos que involucren a la institución. Esto se condice con la función pública que minimiza los riesgos en la actividad funcional. Fuente: elaboración propia. 
Los Factores de Riesgo de Conducta AntiÉtica según el Modelo de Donald R. Cressey aplicado a la Universidad Nacional Mayor de San Marcos

Tabla 6

Pregunta: Tengo poder para causar daño financiero si lo deseo por falta de controles

\begin{tabular}{llcccc}
\hline & & Frecuencia & Porcentaje & Porcentaje válido & Porcentaje acumulado \\
& Muy en desacuerdo & 20 & 35,1 & 35,1 & 35,1 \\
\multirow{3}{*}{ Válido } & En desacuerdo & 17 & 29,8 & 29,8 & 7,9 \\
& Indiferente & 4 & 7,0 & 7,0 & 7,9 \\
& De acuerdo & 16 & 28,1 & 28,1 & 100,0 \\
& Total & 57 & 100,0 & 100,0
\end{tabular}

Nota: El 28\% de los funcionarios entrevistados consideran que los controles institucionales son incapaces de evitar la corrupción. Fuente: elaboración propia.

Tabla 7

Pregunta: Puede darse que supere barreras morales, justificar mi conducta y llevar a cabo delitos fraudulentos

\begin{tabular}{llcccc}
\hline & Frecuencia & Porcentaje & Porcentaje válido & Porcentaje acumulado \\
& & & & 40,4 & 40,4 \\
\multirow{4}{*}{ Válido } & 23 & 40,0 & 28,1 & 68,4 \\
& Muy en desacuerdo & 16 & 28,1 & 19,3 & 100,0 \\
& En desacuerdo & 11 & 19,3 & 12,3 & \\
\hline & De acuerdo & 7 & 12,3 & 100,0 & \\
& Muy de acuerdo & 57 & 100,0 & & \\
\hline
\end{tabular}

Nota: El 31,6 \% de los entrevistados considera que se puede encontrar justificaciones para los actos de corrupción. Fuente: elaboración propia.

Tabla 8

Pregunta: Existe vulnerabilidad en los controles de la universidad

\begin{tabular}{llcccc}
\hline & Frecuencia & Porcentaje & Porcentaje válido & Porcentaje acumulado \\
\cline { 3 - 4 } & & & & 12,3 & 12,3 \\
Válido desacuerdo & 7 & 12,3 & 21,1 & 33,3 \\
& Indiferente & 12 & 21,1 & 54,4 & 87,7 \\
& De acuerdo & 31 & 54,4 & 12,3 & 100,0 \\
& Muydeacuerdo & 7 & 12,3 & 100,0 &
\end{tabular}

Nota: Según el 66,7\% de los encuestados los controles de la UNMSM son vulnerables, lo cual facilitaría la comisión de actos de corrupción. Fuente: elaboración propia.

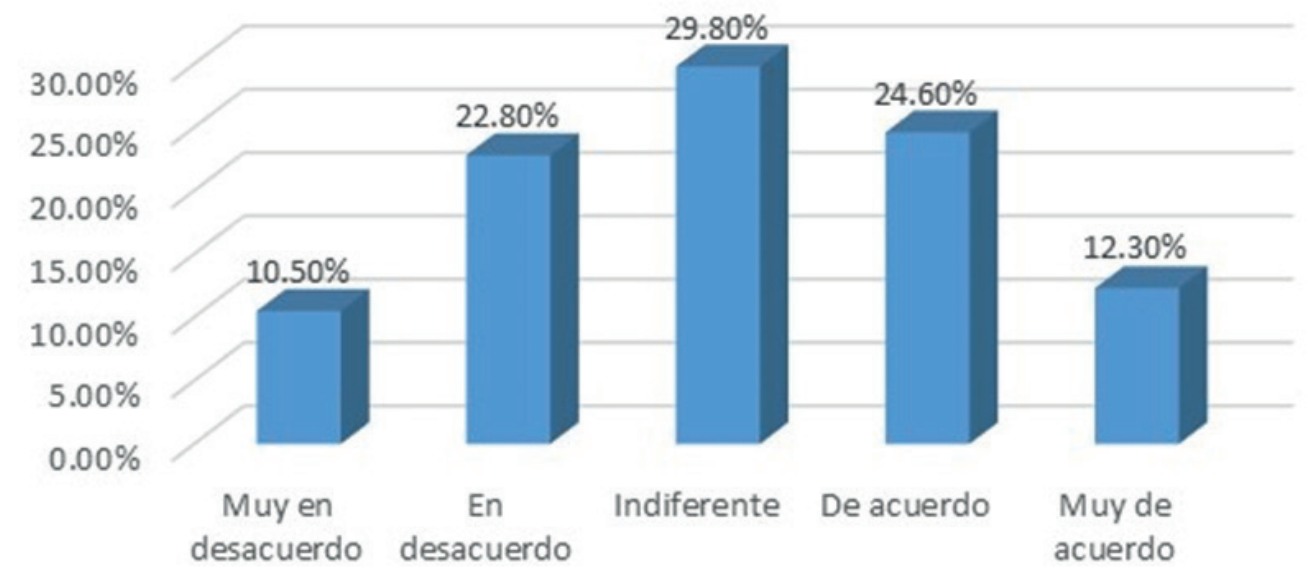

Figura 1. La racionalización de las conductas antiéticas y el nivel funcional de la organización.

Nota: Según los datos obtenidos por las encuestas, encontramos la tendencia directamente proporcional siguiente: A mayor nivel funcional de la organización, la racionalización de las conductas antiéticas es mayor. Elaboración propia. 
Tabla 9

Autopercepción de impunidad

Frecuencia Porcentaje Porcentaje válido Porcentaje acumulado

\begin{tabular}{cccccc} 
& 1 & 9 & 15,8 & 15,8 & 15,8 \\
\multirow{4}{*}{ Válido } & 2 & 14 & 24,6 & 24,6 & 40,4 \\
& 3 & 16 & 28,1 & 28,1 & 68,4 \\
& 4 & 13 & 22,8 & 22,8 & 91,2 \\
& 5 & 5 & 8,8 & 8,8 & 100,0 \\
& 57 & 100,0 & 100,0 &
\end{tabular}

Nota: El 31,6 de los funcionarios encuestados consideran que las conductas antiéticas quedan impunes. Fuente: elaboración propia.

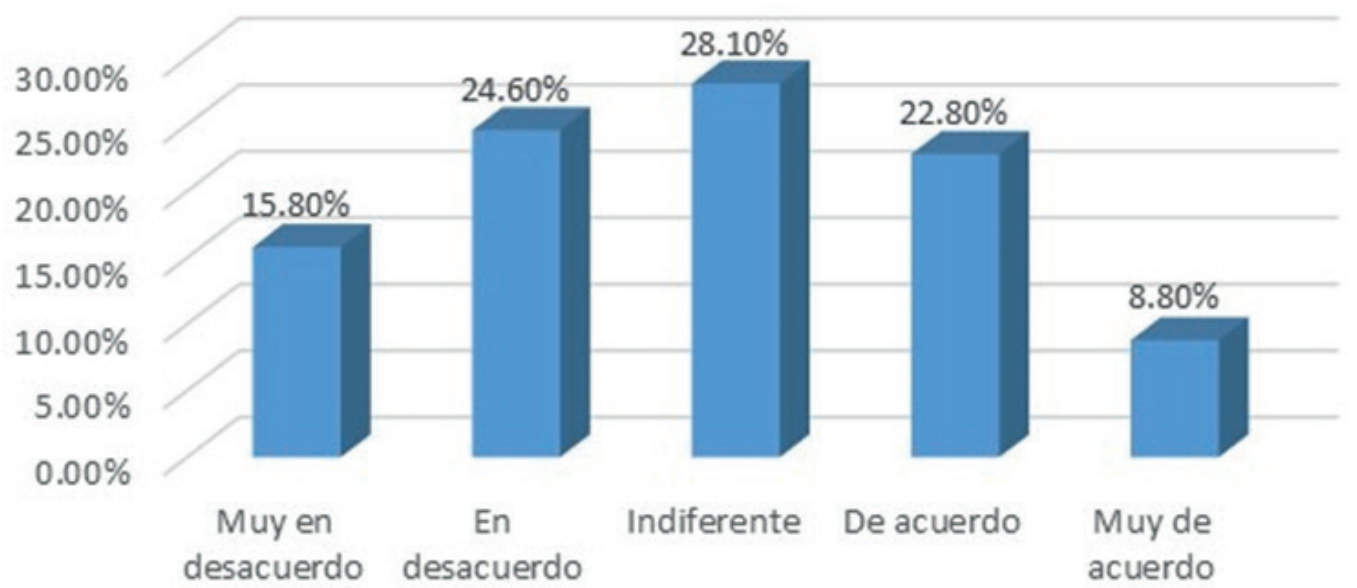

Figura 2. Las características de la corrupción asociadas a la racionalización, están influidas por la autopercepción de impunidad.

Fuente: elaboración propia.

\section{CONCLUSIONES}

1. El grado de racionalización de las conductas antiéticas está relacionado con el nivel funcional de las organizaciones. Esto indica que existe una relación directamente proporcional entre el nivel funcional y la racionalización. Mientras más alto es el grado del funcionario en el organigrama institucional mayor es el grado de racionalización de las conductas riesgosas.

2. La racionalización se presenta con mayor frecuencia con la autopercepción de impunidad. Esto significa que mientras mayor sea la autopercepción de impunidad mayor grado de racionalización de las conductas riesgosas.

\section{RECOMENDACIONES}

Recomendamos establecer programas de capacitación en Ética Profesional y del Servidor Público reforzando las posturas éticas fundamentales que permitan al funcionario de alto nivel enfrentar la autopercepción de impunidad.

Del mismo modo debemos diseñar un nuevo modelo operacional y administrativo de Gestión del órgano de control institucional.

Asimismo, capacitación de personal de los órganos de Control Institucional, el desarrollo de materiales, talleres de capacitación y seminarios varios en auditoría de |desempeño y el desarrollo de un Sistema de Gestión de la Calidad para el nuevo modelo de gestión. 
Por último, se debe desarrollar de un aplicativo para el procedimiento administrativo sancionador y procesos de control masivo en materia de declaraciones juradas, rendición de cuentas, y control simultáneo

\section{REFERENCIAS BIBLIOGRÁFICAS}

Aristóteles (2003). Ética a Nicómaco. Buenos Aires: Editorial Losada.

Barquero Corrales, Alfredo (2003). Ética profesional. San José: Editorial EUNED.

L. Boff (2003), Ética moral la búsqueda de los fundamentos Traducción: Ramón Alfonso Díez Aragón Título del original en portugués Animus / Anima Produçóes Petrópolis, RJ

Cobo, J. (2001). Ética profesional en ciencias humanas y sociales. Madrid: Huerga y Fierro editores.

Contreras, R. (2000). Informe sobre necesidades sociales en Guanajuato. Guanajuato: EUMED.

Cortina, A. y Martínez, E. (2008). Ética. Madrid: Cofás.

Cressey, D. R. (1961). The prison: Studies in institutional organization and change. New York: Holt, Rinehart and Winston de http://ssrn. com/abstract=920625, http://ssrn.com/abstract $=1542759$.

Eigen, P. (2005). Índice de percepción de la corrupción 2004 de transparencia internacional. Transparency International. Recuperado de ELECTRONIC PUBLISHING (SSEP), Inc.; National Bureau of Economic Research (NBER); European Corporate Governance Institute (ECGI).
Estevez, Alejandro M. (2005, EneMar) Reflexiones Teóricas sobre la corrupción: Sus dimensiones política, económica y social. Revista ETXEBERRIA.

Fontán, Pedro y Fullat, Octavi ( 1985). Ethos. Barcelona: Gráficas INSTAR.

García, D. (1996). La ética como instrumento de gestión empresarial. España: Fundación Caixa Castello.

Galor, Sharon, \& Hentschel, Uwe (2013). El uso de los mecanismos de defensa como herramientas de afrontamiento por veteranos israelíes deprimidos y con TEPT. https://www.redalyc.org/articulo.oa?id=3396/339630261005</a>

García. San José (1987). Introducción a la filosofía. Lima.

Jensen, M. (2011). Beyond agency theory: The hidden and heretofore inaccessible power of integrity. Harvard Business School; Social Science

Polo Santillán, M.(2004). La morada del hombre. Lima: CENPRO Editorial e imprenta.

Pope, Jeremy (2000) Confronting Corruption: The Elements of a Nacional Integrity System. Berlin, Germany: Transparency International.

Ramón, J. (2014). Corrupción, ética y función pública en el Perú. QUIPUKAMAYOC Revista de la Facultad de Ciencias Contables Vol. 22 N 41 pp. 5973 UNMSM, Lima - Perú ISSN: 15609103.

Hassemer, W. (1995) Posibilidades jurídicas, policiales y administrativas de una lucha más eficaz contra la corrupción, en Pena y Estado. Corrupción de funcionarios públicos, No 1, Buenos Aires,

Zañartu, M. (1996). Eficiente corrupción y crecimiento con equidad. Bilbao: Universidad de Deusto. 
